\title{
Determinants of smoking-induced deprivation in China
}

\author{
Tingting Yao, ${ }^{1,2}$ Jidong Huang, ${ }^{3}$ Hai-Yen Sung, ${ }^{1}$ Michael K Ong, ${ }^{4}$ Zhengzhong Mao, ${ }^{5}$ \\ Yuan Jiang, ${ }^{6}$ Geoffrey T Fong, ${ }^{7,8,9}$ Wendy Max ${ }^{1}$
}

${ }^{1}$ Institute for Health \& Aging, University of California, San Francisco, California, USA ${ }^{2}$ Center for Tobacco Control Research and Education, University of California, San Francisco, California, USA ${ }^{3}$ Health Policy Center, Institute for Health Research and Policy, University of Illinois at Chicago, Chicago, Illinois, USA ${ }^{4}$ Division of General Internal Medicine and Health Services Research, Department of Medicine, University of California, Los Angeles, California, USA

${ }^{5}$ Huaxi School of Public Health, Sichuan University, Chengdu, China

${ }^{6}$ National Tobacco Control Office, Chinese Center for Disease Control and Prevention, Beiijing, China ${ }^{7}$ Department of Psychology, University of Waterloo, Waterloo, Ontario, Canada ${ }^{8}$ Ontario Institute for Cancer Research, Toronto, Ontario, Canada

${ }^{9}$ School of Public Health and Health Systems, University of Waterloo, Waterloo, Ontario, Canada

\section{Correspondence to} Dr Tingting Yao, Institute for Health \& Aging, University of California, San Francisco, 3333 California Street, Suite 340, San Francisco, CA 94118 , USA; tingting.yao@ucsf.edu

Received 3 January 2014 Revised 12 April 2014 Accepted 14 April 2014 Published Online First 14 May 2014

\section{ABSTRACT \\ Objective Spending on cigarettes may deprive households of other items like food. The goal of this study was to examine the prevalence of and factors associated with this smoking-induced deprivation among adult smokers in China.}

Methods The data came from Waves 1-3 of the International Tobacco Control (ITC) China Survey, conducted from 2006 to 2009 among urban adults aged 18 years or older in China. We focus on the samples of current smokers from six cities $(N=7981)$. Smoking-induced deprivation was measured with the survey question, "In the last six months, have you spent money on cigarettes that you knew would be better spent on household essentials like food?" We examined whether sociodemographic factors, smoking intensity and price paid per pack of cigarettes were associated with smoking-induced deprivation using generalised estimating equations modelling.

Findings $7.3 \%$ of smokers reported smoking-induced deprivation due to purchasing cigarettes. Low-income and middle-income smokers were more likely to have smoking-induced deprivation compared with highincome smokers (adjusted OR (AOR) $=2.06,95 \% \mathrm{Cl} 1.32$ to $2.31 ; \mathrm{AOR}=1.44,95 \% \mathrm{Cl} 1.10$ to 1.69$)$; smokers living in Shenyang (AOR=1.68, 95\% Cl 1.25 to 2.24) and Yinchuan ( $A O R=2.50,95 \% \mathrm{Cl} 1.89$ to 3.32) were more likely to have smoking-induced deprivation compared with smokers living in Beijing. Retired smokers were less likely to have smoking-induced deprivation compared with employed smokers ( $\mathrm{AOR}=0.67,95 \% \mathrm{Cl}$ 0.52 to 0.87$)$. There was no statistically significant relationship between smoking intensity, price paid per pack of cigarettes and smoking-induced deprivation. Conclusions Our findings indicate that certain groups of smokers in China acknowledge spending money on cigarettes that could be better spent on household essentials. Tobacco control policies that reduce smoking in China may improve household living standards by reducing smoking-induced deprivation.

\section{INTRODUCTION}

Smoking has a long-term negative impact on health, causing illness, disability, premature deaths and productivity losses that lead to substantial economic burden. ${ }^{1}$ In addition, smoking may also have a short-term negative impact on household finances and living standards, affecting not only the smoker but the rest of the family members as well. ${ }^{2}$ Spending on cigarettes may crowd-out or deprive households of other expenditures such as food, housing and education, meaning that money is spent on cigarettes instead of other household essentials.
Several studies report this effect in developed countries. A study of low-income British families found that smoking was a strong predictor of financial hardship and low income. ${ }^{3}$ Similarly, after controlling for several indicators of socioeconomic status and demographic factors, Siahpush et $a l^{4}$ found that households reporting tobacco expenditures were more likely to experience financial stress in Australia. Using data from the USA, Busch et $a l^{5}$ found that smokers spend less on housing than non-smokers.

For developing countries, impact of smoking on crowding out or depriving of other expenditures may be especially alarming because the proportion of the population living under the poverty line is larger and smoking prevalence is higher than in developed countries. ${ }^{6}$ Efroymson et al ${ }^{7}$ reported that in Bangladesh, tobacco expenditures exacerbate the effects of poverty and cause substantial deterioration in nutritional status and living standards among the poor. In India, John $e t a l^{8}$ found that expenditures on tobacco were associated with increased rural and urban poverty rates by 1.5 and $0.7 \%$, respectively. John also found that households with tobacco consumption had lower consumption of certain commodities including milk, education and entertainment. ${ }^{9}$ A recent study conducted in Cambodia found that spending on tobacco crowds out expenditures on food for low-income and middle-income households. ${ }^{10}$

The impact of smoking on crowding out or depriving of other household expenditures in China is particularly important because China is the largest consumer of tobacco in the world. Several studies have documented the impact of tobacco expenditures on crowding out other household spending in China. A study conducted in Shanghai in 1995 reported that current smokers spent $17 \%$ of their household income on cigarettes. ${ }^{11}$ The average daily household income for a middle-class family in China was about $\$ 9.80$ in $2010 .{ }^{12}$ Thus, one pack of the most popular brand of cigarette (Yuxi, \$2.90/pack) would account for $30 \%$ of the family's daily income. In the USA, by contrast, daily income averages $\$ 137.33$ and a typical pack of cigarettes costs $\$ 5.72$, or $4 \%$ of daily income. ${ }^{13} 14$ Two studies conducted in China found that purchasing cigarettes reduces household expenditures on food, housing, clothing, education and durable goods consumption. ${ }^{1}{ }^{15}$ Liu et al ${ }^{16}$ found that household spending on cigarettes in China resulted in an increase in the poverty rate in urban and rural areas of 6.4 and $1.9 \%$, respectively. However, none of these studies in China examined the proportion of adult smokers who experienced 
smoking-induced deprivation, which was first defined based on subjective perception by Siahpush et $a l^{17}{ }^{18}$ using survey question ("In the last six months, have you spent money on cigarettes that you knew would be better spent on household essentials like food?"). In addition, while studies conducted in the USA, Canada, the UK, Australia and Mexico have examined the factors associated with smoking-induced deprivation among adult smokers in those countries, ${ }^{1718}$ little research has addressed the correlates of smoking-induced deprivation among Chinese smokers. This study will fill that gap by (1) examining the proportion of adult smokers who reported that their cigarette purchases deprived them of essential household expenditures, and (2) identifying the factors associated with smoking-induced deprivation among adult current smokers in China. This information will help policymakers to make the case that quitting smoking would enhance family welfare in China.

\section{METHODS}

\section{Data source and study design}

The data from Wave 1 (April-August 2006), Wave 2 (October 2007-January 2008) and Wave 3 (May-October 2009) of the International Tobacco Control (ITC) China Survey were analysed, which is a prospective longitudinal survey of adults aged 18 years or older in six cities in China: Beijing, Shanghai, Guangzhou, Changsha, Shenyang and Yinchuan. Starting from Wave 3, Kunming has been added in the ITC China Survey, but we did not include the Kunming sample in this study. These cities were judiciously selected based on their size, geographical representations and levels of economic development. ${ }^{19}$ Using a multistage cluster random sampling design, a representative sample of approximately 800 current smokers and 200 nonsmokers who were registered residents were selected within each city at each wave. Current smokers are defined as those who have smoked 100 cigarettes in their lifetime and are currently smoking at least once a week at the time of interview. Through face-to-face interviews, information on individual's demographic characteristics such as age and gender, smoking behaviour and cigarette purchasing behaviour was collected. The response rates ranged from $39.4 \%$ in Yinchuan to $61.3 \%$ in Shanghai. ${ }^{20} \mathrm{~A}$ more detailed description of the survey methods can be found in Wu et al. ${ }^{20}$

\section{Study sample}

The samples used for this study were restricted to current smokers who participated in all three waves of the ITC China Survey in each city. After excluding observations with missing information on smoking-induced deprivation, sociodemographic characteristics, smoking intensity and price paid per pack of cigarettes. Our final study sample size was 7981 observations.

\section{Measures}

Dependent variable

The dependent variable in this study is smoking-induced deprivation, which was measured by the ITC China Survey question: 'In the last six months, have you spent money on cigarettes that you knew would be better spent on household essentials like food?' Those who responded 'yes' to the question were considered to have smoking-induced deprivation, whereas those who responded 'no' were not. Those who refused to answer or reported unknown status were coded as missing and excluded from our sample as stated above.
Independent variables

In this study, three groups of independent variables were included: (1) sociodemographic characteristics, (2) smoking intensity and (3) price paid per pack of cigarettes. Sociodemographic characteristics are gender, age, marital status, education, monthly household income, employment status and city of residence. Age was categorised as 18-24 years, 2539 years, 40-54 years and 55 years or older. Marital status was classified as married or living together, divorced or separated or widowed, and single. Education was categorised as low (less than high school degree), middle (high school graduate) and high (more than high school degree). Using the income categories for urban areas from the 2010 China Statistics Yearbook, ${ }^{21}$ monthly household income was classified into three categories: low income ( $<1000$ Yuan, equal to US\$147, using the 2009 exchange rate of 6.8 Yuan per dollar ${ }^{21}$ ), middle income (1000-2999 Yuan, equal to US\$147-441) and high income (>3000 Yuan, equal to US\$441). Household size in China varies little due to the onechild policy, so the classification of income categories in our study is based on the size of a typical urban family in Chinathree persons. Employment status was classified as employed, unemployed and retired. Smoking intensity was categorised as light $(\leq 10$ cigarettes per day (CPD)), moderate (11-20 CPD) and heavy $(\geq 21 \mathrm{CPD})$. Price paid per pack of cigarettes was assessed by the question: "On average, how much did you pay for each pack of cigarettes you bought last time?" and classified into four groups using quartiles: <3.5 Renminbi (RMB)/pack, 3.5-10 $\mathrm{RMB} /$ pack, $10-40 \mathrm{RMB} /$ pack and $\geq 40 \mathrm{RMB} /$ pack.

\section{Statistical analysis}

Because of the correlated nature of the longitudinal ITC China Survey data within respondents across survey waves, we used the method of generalised estimating equations $(\mathrm{GEE})^{22-24}$ to examine the factors associated with smoking-induced deprivation among smokers. In the GEE model, the dependent variable was whether or not smokers had experienced smoking-induced deprivation in the last six months (yes/no). The independent variables were sociodemographic characteristics, smoking intensity and price paid per pack of cigarettes. In GEE modelling, gender and city of residence were treated as time-invariant, whereas the other independent variables were treated as time-varying variables. We specified the GEE model with binomial distribution and a logit link. We also specified an unstructured within-subject correlation structure based on the lowest 'quasi-likelihood under the independence model criterion (QIC)' among various structures of the covariance matrix of the error terms (independent, autoregressive, exchangeable, 1-dependent and unstructured). All analyses were conducted with STATA, V.11.0 $0^{25}$ and were also weighted to ensure that results were representative of smokers in the six cities included. $^{20}$ Adjusted ORs (AOR) and the corresponding 95\% CIs were computed to assess the strength of association. A twotailed $\mathrm{p}$ value of $<0.05$ was considered statistically significant.

\section{RESULTS}

Table 1 shows the characteristics of the study sample. Only $4.6 \%$ of smokers in our sample were female. Most smokers in our sample were aged 40 and older (84.4\%) and married or living together $(90.8 \%)$. Sixteen per cent of the sample reported low income, while 46.2 and $37.8 \%$ reported middle and high income, respectively. $19.9 \%$ of them had achieved high education status, and a majority of the sample were employed (59.9\%). Nearly half of the sample were moderate smokers 
Table 1 Characteristics of smokers in our sample in Waves 1-3 of the ITC China Survey $(\mathrm{N}=7981)$

\begin{tabular}{|c|c|c|}
\hline Characteristic & $\mathbf{n}$ & $\%$ \\
\hline \multicolumn{3}{|l|}{ Gender } \\
\hline Male & 7611 & 95.4 \\
\hline Female & 370 & 4.6 \\
\hline \multicolumn{3}{|l|}{ Age } \\
\hline $18-24$ & 55 & 0.7 \\
\hline $25-39$ & 1188 & 14.9 \\
\hline $40-54$ & 4024 & 50.4 \\
\hline $55+$ & 2714 & 34.0 \\
\hline \multicolumn{3}{|l|}{ Marital status } \\
\hline Married or living together & 7247 & 90.8 \\
\hline Divorced or separated or widowed & 466 & 5.8 \\
\hline Single & 268 & 3.4 \\
\hline \multicolumn{3}{|l|}{ Monthly household income } \\
\hline Low & 1274 & 16.0 \\
\hline Middle & 3687 & 46.2 \\
\hline High & 3020 & 37.8 \\
\hline \multicolumn{3}{|l|}{ Education } \\
\hline Low & 930 & 11.7 \\
\hline Middle & 5462 & 68.4 \\
\hline High & 1589 & 19.9 \\
\hline \multicolumn{3}{|l|}{ Employment status } \\
\hline Employed & 4780 & 59.9 \\
\hline Unemployed & 1012 & 12.7 \\
\hline Retired & 2189 & 27.4 \\
\hline \multicolumn{3}{|l|}{ City of residence } \\
\hline Beijing & 1577 & 19.8 \\
\hline Shenyang & 991 & 12.4 \\
\hline Shanghai & 1673 & 21.0 \\
\hline Changsha & 1414 & 17.7 \\
\hline Guangzhou & 1139 & 14.3 \\
\hline Yinchuan & 1187 & 14.9 \\
\hline \multicolumn{3}{|l|}{ Smoking intensity (cigarettes per day) } \\
\hline Light $(0-10)$ & 2785 & 34.9 \\
\hline Moderate (11-20) & 3933 & 49.3 \\
\hline Heavy $(21+)$ & 1263 & 15.8 \\
\hline \multicolumn{3}{|l|}{ Price paid per pack of cigarette } \\
\hline$<3.5$ RMB/pack & 1716 & 21.5 \\
\hline 3.5-10 RMB/pack & 5164 & 64.7 \\
\hline 10-50 RMB/pack & 1061 & 13.3 \\
\hline$\geq 40 \mathrm{RMB} /$ pack & 48 & 0.6 \\
\hline Total & 7981 & \\
\hline
\end{tabular}

ITC, International Tobacco Control.

(49.3\%), and 64.7\% reported paying 3.5-10 RMB for a pack of cigarette.

\section{Model selection}

As we considered the model with the lowest QIC to be the most parsimonious, we chose the model with unstructured working correlation matrix (see Table 2).

\section{Smoking-induced deprivation and associated factors}

The percentage of smokers who reported that they spent money on cigarettes that they knew would be better spent on household essentials like food was 7.3\% (see Table 3). After controlling for other covariates, the GEE model results indicate that smoking-induced deprivation was more likely among
Table 2 QIC of each working correlation matrix

\begin{tabular}{ll}
\hline Working correlation matrix & QIC \\
\hline Independent & 3952.999 \\
AR(1) & 3952.114 \\
Exchangeable & 3952.110 \\
1-Dependent & 3952.117 \\
Unstructured & 3952.103 \\
\hline
\end{tabular}

low-income and middle-income than high-income smokers $(\mathrm{AOR}=2.06,95 \%$ CI 1.32 to $2.31 ; \mathrm{AOR}=1.44,95 \%$ CI 1.10 to 1.69). In terms of the marginal effects, the probability of reporting smoking-induced deprivation increased significantly by $4.3 \%$ higher among adults with low income $(\mathrm{p}<0.05)$ and $2.3 \%$ higher among those with middle income $(\mathrm{p}<0.05)$ compared with the high-income group. The results also show that retired smokers were less likely to have smoking-induced deprivation than employed smokers ( $\mathrm{AOR}=0.67,95 \% \mathrm{CI} 0.52$ to 0.87). Smokers living in Shenyang and Yinchuan were more likely to have smoking-induced deprivation than smokers living in Beijing $(\mathrm{AOR}=1.68,95 \% \mathrm{CI} 1.25$ to 2.24 ; $\mathrm{AOR}=2.50,95 \%$ CI 1.89 to 3.32 ). No statistically significant relationship was found between smoking intensity, price paid per pack of cigarettes and smoking-induced deprivation. We have also checked the interaction effects between (1) income and city, (2) income and employment status, and (3) income and price paid per pack of cigarettes, and found that none of them was statistically significant.

\section{DISCUSSION}

Our findings that lower income smokers were more likely to have smoking-induced deprivation are consistent with previous findings from a study conducted in developed countries ${ }^{17}$ and a study conducted in Mexico. ${ }^{18}$ This emphasises the need to implement tobacco prevention and cessation programmes that specifically target low-income smokers in order to reduce smoking-induced deprivation of household essentials.

Our study also found that smokers residing in Shenyang and Yinchuan were more likely to have smoking-induced deprivation than smokers living in Beijing. This might be because these cities are less economically developed than Beijing. ${ }^{12}$

We found no statistically significant relationship between smoking intensity and smoking-induced deprivation. This differs from the findings of two previous studies conducted by Siahpush et al. ${ }^{17}$ One of their studies found that smokers who had higher levels of nicotine dependence had higher odds of smoking-induced deprivation. Our results may differ because smoking intensity was measured differently in our study than in this study. In our study, smoking intensity was based on number of cigarettes smoked per day, while Siahpush et al ${ }^{17}$ measured nicotine dependence using the Heaviness of Smoking Index based on a composite of time to first cigarette smoked after waking and number of cigarettes smoked per day. The other study found that smoking five or more CPD was associated with higher odds of smoking-induced deprivation. We reanalysed our data using the same cut-off value (five CPD) for smoking intensity in our model, but we still found no statistically significant relationship between smoking intensity and smoking-induced deprivation. Future studies are needed to provide a better understanding of the relationship between smoking intensity, dependence and smoking-induced deprivation in China. In 
Table 3 Percentages of smokers who reported smoking-induced deprivation by characteristics and adjusted ORs from the GEE model

\begin{tabular}{|c|c|c|c|}
\hline Characteristic & $\begin{array}{l}\% \text { Reporting } \\
\text { smoking-induced } \\
\text { deprivation }\end{array}$ & Adjusted OR & $95 \% \mathrm{Cl}$ \\
\hline Total & 7.3 & & \\
\hline \multicolumn{4}{|l|}{ Gender } \\
\hline Male & 7.2 & Reference & \\
\hline Female & 10.0 & 1.40 & 0.99 to 1.95 \\
\hline \multicolumn{4}{|l|}{ Age } \\
\hline $18-24$ & 5.5 & 0.61 & 0.17 to 2.12 \\
\hline $25-39$ & 7.1 & 0.98 & 0.71 to 1.34 \\
\hline $40-54$ & 8.2 & 1.22 & 0.96 to 1.54 \\
\hline $55+$ & 6.1 & Reference & \\
\hline \multicolumn{4}{|l|}{ Marital status } \\
\hline Married or living together & 7.2 & Reference & \\
\hline $\begin{array}{l}\text { Divorced or separated or } \\
\text { windowed }\end{array}$ & 10.7 & 1.35 & 0.90 to 1.83 \\
\hline Single & 4.9 & 0.61 & 0.41 to 1.72 \\
\hline \multicolumn{4}{|l|}{ Monthly household income } \\
\hline Low & 13.9 & $2.06^{*}$ & 1.32 to 2.31 \\
\hline Middle & 7.5 & $1.44^{*}$ & 1.10 to 1.69 \\
\hline High & 4.3 & Reference & \\
\hline \multicolumn{4}{|l|}{ Education } \\
\hline Low & 10.4 & 1.56 & 0.96 to 1.85 \\
\hline Middle & 7.4 & 1.19 & 0.94 to 1.51 \\
\hline High & 5.2 & Reference & \\
\hline \multicolumn{4}{|l|}{ Employment status } \\
\hline Employed & 7.1 & Reference & \\
\hline Unemployed & 12.5 & 1.01 & 0.80 to 1.27 \\
\hline Retired & 5.4 & $0.67^{*}$ & 0.52 to 0.87 \\
\hline \multicolumn{4}{|l|}{ City } \\
\hline Beijing & 5.0 & Reference & \\
\hline Shenyang & 10.2 & $1.68^{*}$ & 1.25 to 2.24 \\
\hline Shanghai & 3.9 & 0.88 & 0.64 to 1.20 \\
\hline Changsha & 8.0 & 1.29 & 0.96 to 1.74 \\
\hline Guangzhou & 6.2 & 1.18 & 0.88 to 1.58 \\
\hline Yinchuan & 12.9 & $2.50^{*}$ & 1.89 to 3.32 \\
\hline \multicolumn{4}{|c|}{ Smoking intensity (cigarettes per day) } \\
\hline Light (0-10 CPD) & 6.9 & Reference & \\
\hline Moderate (11-20 CPD) & 7.0 & 1.01 & 0.83 to 1.23 \\
\hline Heavy $(21+C P D)$ & 8.9 & 1.23 & 0.95 to 1.58 \\
\hline \multicolumn{4}{|c|}{ Price paid per pack of cigarette } \\
\hline$<3.5$ RMB/pack & 9.6 & Reference & \\
\hline 3.5-10 RMB/pack & 8.4 & 0.99 & 0.80 to 1.24 \\
\hline 10-40 RMB/pack & 7.3 & 0.99 & 0.79 to 1.24 \\
\hline$\geq 40$ RMB/pack & 5.9 & 0.90 & 0.70 to 1.15 \\
\hline
\end{tabular}

addition, we found price paid per pack of cigarettes had no association with smoking-induced deprivation, which is consistent with the study conducted in Mexico by Siahpush et $a l^{18}$ This might be because smokers may reduce their cigarette consumption when cigarette prices increase. ${ }^{26}$

While no previous studies have examined the association between employment status and smoking-induced deprivation from cigarette expenditures, our study found that retired smokers are less likely to report smoking-induced deprivation than employed smokers. Possible explanations include that retirees are collecting pensions that are adequate to cover their expenses or that the household size of retired people is smaller and so expenses are reduced. Another reason could be this survey was conducted in big urban cities in China, where people including retirees are much wealthier than people in other cities. Further research is needed to explore this association.

The percentage of smokers who reported having smoking-induced deprivation (7.3\%) in this study was lower than that reported in Australia (33\%), the UK (20\%), the USA $(28 \%)$ and Canada (28\%). ${ }^{17}$ China differs from these countries in that there is huge price variation (from less than US\$1 per pack to more than US $\$ 30$ per pack) among cigarettes brands in China so that smokers have multiple price points to choose from what might not appear to be 'cheaper cigarettes' than usual. Another explanation might be that our data were limited to six large urban areas, which may have a lower percentage of smokers reporting smoking-induced deprivation compared with rural China, where incomes tend to be lower. One more explanation could be the survey question (Have you spent money on cigarettes that you knew would be better spent on household essentials like food?) was asked for expenditure patterns 6 months ago, so there might be recall bias and then underestimate the percentage of smoking-induced deprivation.

Our data came from the ITC China Survey, which did not collect household expenditures data on other household essentials like food, housing and education, so it does not allow us to compare the household expenditure patterns of smokers and non-smokers. In addition, the ITC China Survey is not a nationally representative sample, although it is a representative sample of adults living in the selected urban cities covering about $10 \%$ of the total population in China. ${ }^{20}$ Given that the vast majority of the smoking population still lives in rural areas in China, caution needs to be exercised in generalising the findings to rural areas.

The findings of our study imply that reducing smoking could result in greater household expenditures available for spending on food and other household essentials among certain Chinese smokers, especially those of lower income and those living in Shenyang and Yinchuan. Thus, in addition to health benefits, smoking cessation and reduction might also lead to an improvement in living standards in China.

\section{What this paper adds}

- In China, spending on cigarettes may deprive households of other household items such as food.

- Low-income smokers and smokers living in Shenyang and Yinchuan are more likely than high-income smokers and smokers living in Beijing, respectively, to report that they had experienced smoking-induced deprivation. Retired smokers were less likely to report smoking-induced deprivation than employed smokers in China.

- Tobacco control policies that reduce smoking in China may improve household living standards by reducing smoking-induced deprivation.

Acknowledgements The authors would like to thank the Chinese Center for Disease Control and Prevention (CDC), and the local CDC representatives in each city for their collection of data, and members of the University of California, San Francisco Writer's Task Force, for their helpful comments and suggestions.

Contributors GTF and YJ obtained funding and collected data. TY, JH, WM, H-YS, MKO and ZM participated in the data analysis and interpretation of the results. All drafts were written by TY and commented on by all authors. All authors read and approved the final manuscript. 
Funding The ITC China Project was supported by grants from the US National Cancer Institute (R01 CA125116 and P01 CA138389), the Roswell Park Transdisciplinary Tobacco Use Research Center (P50 CA111236), the Robert Wood Johnson Foundation (045734); the Canadian Institutes of Health Research (57897, 79551 and 115016), and the Chinese Center for Disease Control and Prevention. Additional support was provided by the US National Institutes of Health Fogarty International Center (grant R01 TW009295) and National Cancer Institute; the US National Cancer Institute (Grant CA-113710); California Tobacco-Related Disease Research Program, Cornelius Hopper Diversity Award Supplement (20CA- 0102); and the University of California, San Francisco Dorothy Pechman Rice Postdoctoral Fellowship. Additional support was provided to Geoffrey T Fong from a Senior Investigator Award from the Ontario Institute for Cancer Research and a Prevention Scientist Award from the Canadian Cancer Society Research Institute, and to Jidong Huang by a grant from the Canadian International Development Research Centre (grant no. 106839-001), titled 'Impact of Tobacco Tax and Price Policies on Tobacco Use in China'.

Competing interests None declared.

Patient consent Obtained.

Ethics approval Ethics approval was obtained from the Office of Research at the University of Waterloo (Waterloo, Canada) and the Institutional Review Boards at the Roswell Park Cancer Institute (Buffalo, USA), the Cancer Council Victoria (Victoria, Australia), and the Chinese Center for Disease Control and Prevention (Beijing, China).

Provenance and peer review Not commissioned; externally peer reviewed.

\section{REFERENCES}

1 US Department of Health and Human Services. The health consequences of smoking: a report of the Surgeon General. Atlanta, Georgia: US Department of Health and Human Services, Centers for Disease Control and Prevention, National Center for Chronic Disease Prevention and Health Promotion, Office on Smoking and Health, 2004.

2 Wang $\mathrm{H}$, Sindelar JL, Busch SH. The impact of tobacco expenditure on household consumption patterns in rural China. Soc Sci Med 2006;62:1414-26.

3 Marsh A, McKay S. Poor smokers. London: Policy Studies Institute, 1994.

4 Siahpush M, Borland R, Scollo M. Smoking and financial stress. Tob Control 2003;12:60-6.

5 Busch SH, Jofre-Bonet M, Falba TA, et al. Burning a hole in the budget: tobacco spending and its crowd-out of other goods. Appl Health Econ Health Policy 2004;3:263-72.

6 Bobak M, Jha P, Nguyen S, et al. Poverty and smoking. Tobacco control in developing countries. Oxford: Oxford University Press, 2000:41-61.
7 Efroymson D, Ahmed S, Townshend J, et al. Hungry for tobacco: an analysis of the economic impact of tobacco consumption on the poor in Bangladesh. Tob Control 2001;10:212-17.

8 John $\mathrm{R}$, Sung HY, Max W, et al. Counting 15 million more poor in India, thanks to tobacco. Tob Control 2011;20:349-52.

9 John R. Crowd out effect of tobacco expenditure and its implications on household resource allocation in India. Soc Sci Med 2008;66:1356-67.

10 John R, Ross $\mathrm{H}$, Blecher $\mathrm{E}$. Tobacco expenditures and its implications for household resource allocation in Cambodia. Tob Control 2012;21:341-6.

11 Gong YL, Koplan JP, Feng W, et al. Cigarette smoking in china: prevalence, characteristics, and attitudes in Minhang District. JAMA 1995;274:1232-3.

12 China Statistical Yearbook. China Statistical Press. 2011.

13 DeNavas-Walt C, Proctor BD, Smith JC. Income, Poverty, and Health Insurance Coverage in the United States: 2010. U.S. Census Bureau. http://www.census.gov/ prod/2011 pubs/p60-239.pdf (accessed 12 Aug 2012).

14 World Health Organization. WHO Report on the Global Tobacco Epidemic, 2011. http://www.who.int/tobacco/surveillance/policy/country_profile/usa.pdf (accessed 12 Aug 2012).

15 Hu TW, Mao ZZ, Liu YL, et al. Smoking, standard of living, and poverty in China. Tob Control 2005;14:247-50.

16 Liu YL, Rao K, Hu TW, et al. Cigarette smoking and poverty in China. Soc Sci Med 2006;63:2784-90. 12 June 2012

17 Siahpush M, Borland R, Yong $\mathrm{H}-\mathrm{H}$. Sociodemographic and psychosocial correlates of smoking-induced deprivation and its effect on quitting: findings from the International Tobacco Control Policy Evaluation Survey. Tob Control 2007;16:e2.

18 Siahpush M, Thrasher JF, Yong HH, et al. Cigarette prices, cigarette expenditure and smoking induced deprivation: findings from the International Tobacco Control Mexico survey. Tob Control 2013;22:223-6.

19 International Tobacco Control project website: http://www.itcproject.org/countries

20 Wu CB, Thompson ME, Fong GT, et al. Methods of the International Tobacco Control (ITC) China Survey. Tob Control 2010;19(Suppl 2):i1-5.

21 China Statistical Yearbook (2010). China Statistical Press.

22 Hardin J, Hilbe J. Generalized estimating equations. London: Chapman and Hall/ CRC, 2003. ISBN 978-1-58488-307-4.

23 Diggle PJ, Heagerty $\mathrm{P}$, Liang KY, et al. Analysis of longitudinal data. Oxford Statistical Science Series, 2002. ISBN 978-0-19-852484-7.

24 Liang K-Y, Zeger S. Longitudinal data analysis using generalized linear models. Biometrika 1986;73:13-22.

25 STATA, version 11.0. Stata Corporation, College Station, TX, USA.

26 Hu TW, Mao Z, Shi J, et al. Tobacco taxation and its potential impact in China. Paris: International Union Against Tuberculosis and Lung Disease, 2008. 